\section{Cardiolascular and Interventional Radiology}

(C) Springer-Verlag New York Inc. 1988

\title{
Arterial Anatomy and Arteriographic Diagnosis of Arteriogenic Impotence
}

\author{
Wolfgang Bähren, ${ }^{1}$ Helmut Gall, ${ }^{2}$ Wolfgang Scherb, ${ }^{3}$ Christian Stief, ${ }^{4}$ and Walter Thon ${ }^{4}$ \\ Departments of 'Radiology. 'Dernatology, "Neurology and Psychiatry. and ${ }^{4}$ Urology, Federal Army Hospital, Ulm, West Germany
}

\begin{abstract}
One hundred twenty-six bilateral selective arteriographic examinations of the iliopudendal vascular tree were performed after comprehensive multidisciplinary evaluation in patients with chronic erectile dysfunction. Best imaging results were obtained by performing the arteriography under epidural anesthesia after intracavernous injection of a vasoactive drug combination. The arteriography is mandatory prior to revascularization procedures. It is further indicated in primary erectile dysfunction and posttraumatic erectile failure. The importance of cavernosography and selective arteriography in primary erectile dysfunction is stressed. Increasing knowledge about the influence of vasoactive drugs on penile hemodynamics has led to its application in diagnosis and therapy of erectile dysfunction. Pharmacocavernosography, Doppler-ultrasound of penile arteries after intracavernous injection of a vasoactive drug combination, and pharmacoarteriography are refined techniques to prove a vascular etiology of erectile dysfunction. The results of the morphologic studies of the vascular system are correlated with functional testing of erectile capacity by intracavernous application of a papaverinephentolamine drug combination.
\end{abstract}

Key words: Pharmacoarteriography-Erectile dysfunction, primary, posttraumatic-Vasoactive drugs-Penile arteries, anatomy-Congenital anomalies-Arteriosclerosis

The arteriographic assessment of morphological changes in pudendal and penile arteries represents the crucial step in diagnosis of vascular erectile dys-

Address reprint requests to: PD Dr. W. Bähren, Abt. Radiologie. Oberer Eselsberg 40.7900 Ulm. West Germany function, especially prior to invasive therapeutic procedures.

Ginestie and Romieu [1] first described an arteriographic method that regularly demonstrated peripheral pudendal and penile vessels with good contrast. They gave detailed information on catheterization, projection, and amount and flow-rate of contrast medium that is still valid today [1]. Further refinement of the technique by the use of artificial erection and intracavernous application of vasoactive substances has led to marked improvement in the quality of visualization of distal vessels (Fig. 1) [2-5].

After careful evaluation of preceding noninvasive investigations, a valid indication must exist prior to invasive arteriography.

\section{Indications for Selective Arteriography}

Arteriography as the only investigation is inadequate because more than $50 \%$ of the patients with chronic erectile dysfunction reveal more than one pathophysiologic factor (e.g., arterial, venous, neurogenic, psychogenic, hormonal) as the cause of their erectile failure [2]. Morphologic and functional assessment of the arterial and venous penile supply are necessary to evaluate a possible vascular basis for impaired erectile function. Therapeutically relevant information can be expected if the penile Doppler and pharmacologic testing with vasoactive substances suggests a hemodynamically significant disturbance of arterial inflow [6]. If pathologic neurologic results are shown by neurologic examination and neurophysiologic tests (BCR-latency measurements, somato-sensory-evoked potentials of pudendal nerve. EMG), the patient most likely will not benefit from operative revascularization procedures. For this reason, a neurophysiologic evaluation should rule out neurologic damage prior to an- 


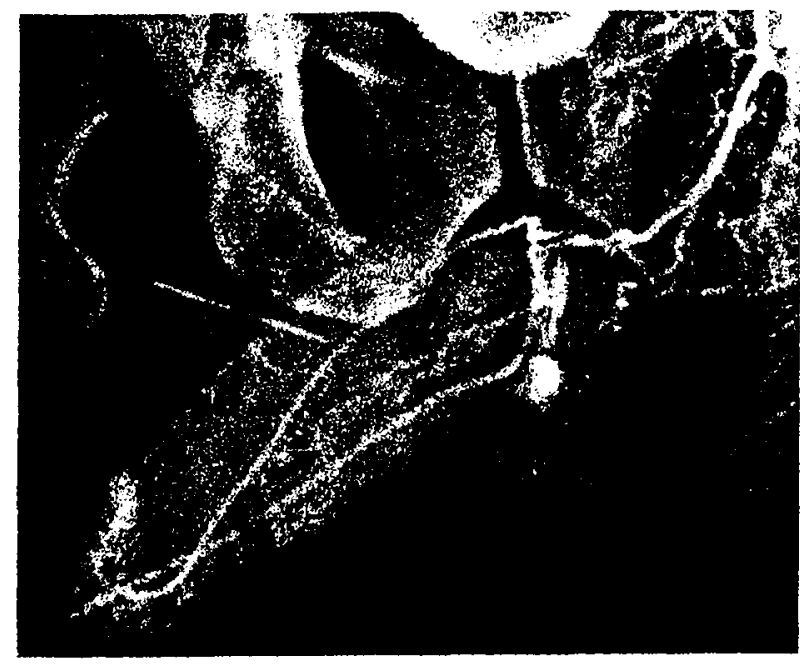

Fig. 1. Selective left pharmacoarteriography with epidural anesthesia. (1) penile artery, (2) dursal penile artery, (3) cavernosial artery with helicine arteries, (4) bulbar artery. (5) urethal artery. (6) perineal artery. (arrow) shunt arteries from cavernosal to urethral artery.

giography, and still more important, prior to operative arterial bypass.

Indications for arteriography can be defined as follows:

Isolated arteriogenic erectile dysunction: This is to determine the possibility of revascularization when Doppler-ultrasound and testing with vasoactive substances suggest pathologic inflow. For this group of patients the upper age limit should be about 50 years. With increasing age, revascularization procedures seem to be less effective [7].

Arteriogenic erectile dysfunction: Indicated when percutaneous transluminal angioplasty ( $\mathrm{P}$ TA) is planned in major pelvic vessels. Isolated stenoses or occlusions of the major pelvic arteries can be treated by PTA without injury to the neural structures that control the erectile function [8, 9] (Fig. 2). Positive effects on penile hemodynamics can only be expected if there is no additional distal occlusion or stenosis in pudendal or penile arteries, especially at the level of the urogenital diaphragm.

Primary erectile dysfunction: Arterial malformation alone or combined with additional causes can be observed in over $60 \%$ of patients with primary erectile dysfunction [2]. Even if there is no chance for promising operative procedures, the positive confirmation of the organic nature gives tremendous psychologic relief to these young patients. Moreover, it prevents unnecessary, costly, and unsuccessful psychotherapy.

Postraumatic erectile dysfinction: Arterial revascularization shows good results in posttraumatic erectile dysfunction if there is no complicating nerve injury present [10]. Angiography and neurophysiologic examination are mandatory preoperatively. Since much pelvic trauma occurs in traffic accidents, it is often necessary for insurance or legal purposes to demonstrate the vascular and/or neurogenic etiology of erectile dysfunction.

The arteriographic clarification of pudendal and penile morphology requires detailed knowledge of anatomy and variations in the hypogastric arterial tree. For interpretation of the arteriograms it is also necessary to be acquainted with hemodynamics, pathophysiology, and clinical appearance of vascular erectile dysfunction. To produce arteriograms of high diagnostic quality, refined arteriographic techniques, including vasoactive substances, must be applied.

\section{Pharmacological Testing Prior to Arteriography}

Functional testing of vasomotor erectile capacity by intracavernous (IC) application of a vasoactive drug combination has proven valuable in differentiating between nonvascular causes, pathologically diminished inflow, and pathologically increased outflow [6. 11]. For this purpose we use a mixture of papaverine $(15 \mathrm{mg} / \mathrm{ml})$ and phentolamine $(0.5 \mathrm{mg} / \mathrm{ml})$ for $\mathrm{IC}$ injection to individually define the dosage required for complete erection in a standardized manner. Doses range from $0.25->3 \mathrm{ml}$. After administration of $0.5 \mathrm{ml}$, normal subjects $(n=10)$ achieve a complete erection within 5-8 min that lasts at least $\frac{1}{2} \mathrm{~h}$.

Two hundred consecutive patients with erectile dysfunction of more than 1-year duration were studied by a multidisciplinary approach which included a standard intracavernosal injection of the vasoactive mixture. The multidisciplinary findings correlated well with the $\mathrm{IC}$ dose needed for full erection The group without pathological hemodynamic findings $(n=36)$ needed an average dose of $0.67 \mathrm{ml}$ (range $0.5-1.5 \mathrm{ml}$ ). The group with pathologic in-

Fig. 2. Vascular erectile dysfunction, pathological inflow due to atherosclerotic stenosis. A 44-year-old patient with erectile dysfunction for the past 5 years. A Initial pelvic arteriogram shows severe stenoses in the right common iliac artery and at the origin of right internal iliac artery (arrow). B There are no atherosclerotic occlusions or major stenoses of pudendal and penile arteries on righe selective arteriography. No major obstructions were present on the left. C PTA catheter in pusition via left femoral approatch in crossover technique. D Result after PTA of common and internal iliac artery shows improvement radiographically. There wits only moderate clinical response because of additional venous leakage. 

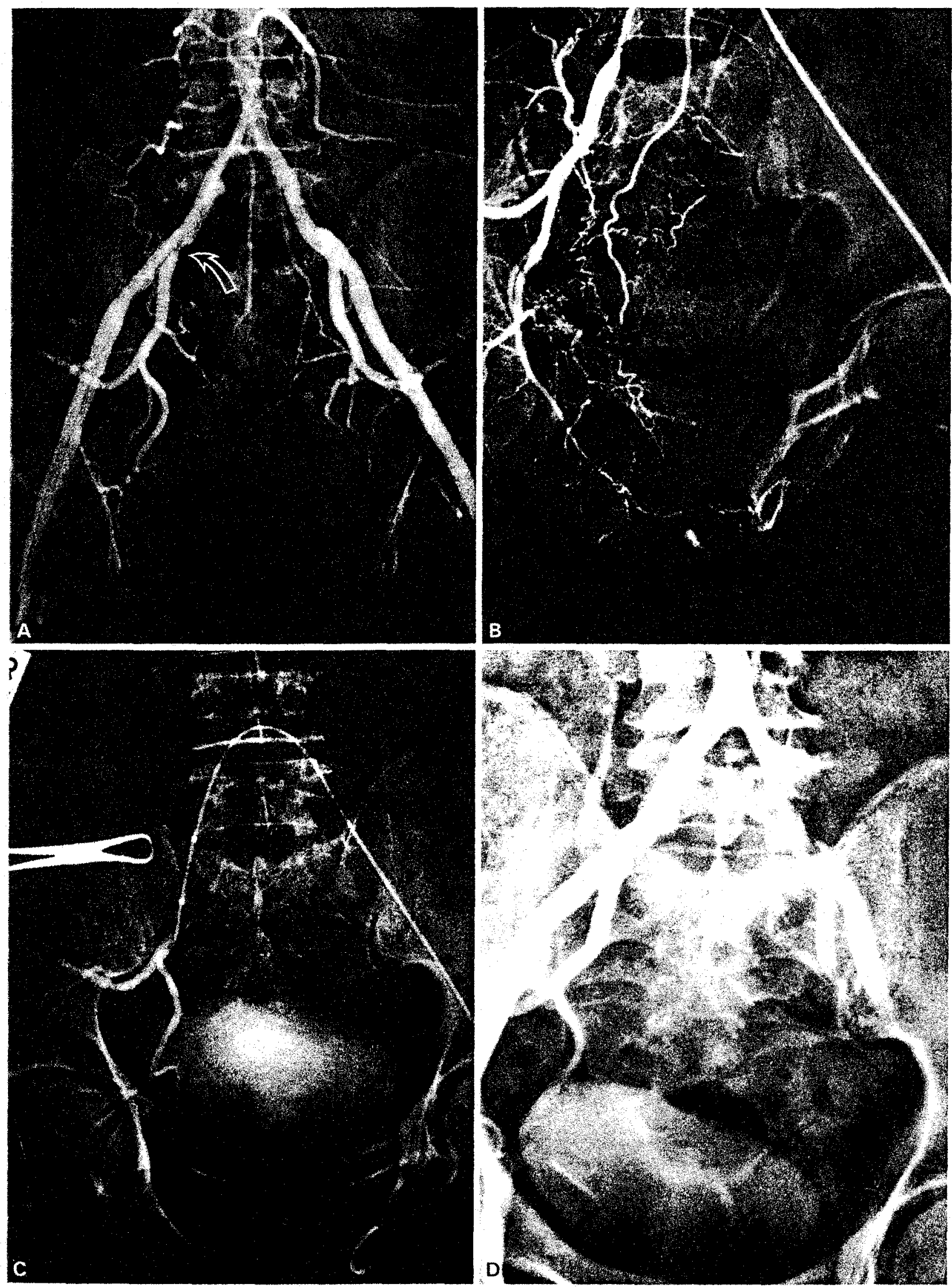
flow (i.e., arterial) conditions $(n=107)$ needed an average dose of $1.07 \mathrm{ml}$ (range $0.5-2.5$ ). In the group with pathologic outflow conditions (i.e.. cavernosal leak) $(n=57), 18$ patients reached full erections with an average dose of $2.1 \mathrm{ml}$ (range $1-3$ $\mathrm{ml}$ ). Thirty-nine patients were nonresponders and after $3 \mathrm{ml}$ reacted with tumescence only.

\section{Arteriographic Technique}

A detailed explanation about possible consequences of the planned diagnostic procedure, side effects, and complications, as well as informed consent, are mandatory.

The region to be investigated extends from the infrarenal aorta to the terminal branching of penile vessels. Initially, the terminal aorta and major pelvic vessels are demonstrated by either conventional pelvic arteriography or by intraarterial digital subtraction angiography. For the pelvic series, the distal abdominal aorta is percutaneously catheterized from the right femoral artery. A 5 French pigtail catheter is placed above the aortic bifurcation. Fifty milliliters of nonionic contrast medium (iopamidol-Solutrast 370) is injected with a flow rate of 18 $\mathrm{ml} / \mathrm{sec}$ and six exposures are performed. The region to be filmed should include the aortic bifurcation and the root of the penis. In most cases arteriography is done prior to surgery on hypogastric or pudendal-penile arteries. The course and origin of the inferior epigastric artery must be determined. For that reason, this series cannot be omitted.

After the examination of the major pelvic vessels, selective arteriography of the hypogastric arteries is performed. Because of possible contributing arterial anastomoses and various collateral arteries, selective arteriography should be done bilaterally even if Doppler seems to show involvement of one side only. After completion of the pelvic series, a guide wire $(0.35 \times 150 \mathrm{~cm})$ is placed into the external iliac artery via the pigtail catheter in crossover technique. The pigtail catheter is replaced by a visceral catheter (C 2) and the left hypogastric artery is selectively catheterized. The tip of the catheter should not extend beyond the branching of the internal iliac artery so as not to miss an accessory pudendal artery that originates from the gluteal or obturator artery.

The patient is placed in a $20-30^{\circ}$ left posterior oblique projection, and the penis is placed and fixed on the right thigh. After IC injection of papaverinephentolamine, tumescence of the penis appears (dosage depends on preangiographic testing and varies from 0.5 to $1.5 \mathrm{ml}$ ) and $50 \mathrm{ml}$ of contrast medium is injected at a flow rate of $4 \mathrm{ml} / \mathrm{sec}$. It is
Table 1. Arteriographic quality criteria and frequency

\begin{tabular}{|c|c|c|c|}
\hline Range & Visible structures & $\begin{array}{l}\text { With } \\
\text { vasoactive } \\
\text { drugs }\end{array}$ & $\begin{array}{l}\text { Without } \\
\text { vasoactive } \\
\text { drugs }\end{array}$ \\
\hline 1 & $\begin{array}{l}\text { Int. pudendal artery } \\
\text { Penile arteries with } \\
\text { terminal branching } \\
\text { Helicine arteries } \\
\text { Shunt arteries }\end{array}$ & $94(64.4 \%)$ & $12(10.7 \%)$ \\
\hline 2 & $\begin{array}{l}\text { Int. pudendal artery } \\
\text { Penile arteries } \\
\text { Helicine arteries with } \\
\text { low contrast } \\
\text { Shunt arteries with } \\
\text { low contrast }\end{array}$ & $40(27.4 \%)$ & $54(48.2 \%)$ \\
\hline 3 & $\begin{array}{l}\text { Int. pudendal artery } \\
\text { Main stem of penile } \\
\text { arteries }\end{array}$ & $12(8.2 \%)$ & $36(32.2 \%)$ \\
\hline 4 & $\begin{array}{l}\text { Int. pudendal artery } \\
\text { Main stem of penile } \\
\text { arteries-low contrast }\end{array}$ & $0(0 \%)$ & $4(3.6 \%)$ \\
\hline 5 & $\begin{array}{l}\text { Int. pudendal artery } \\
\text { - low contrast } \\
\text { No penile arteries }\end{array}$ & $0(0 \%)$ & $6^{3}(5.3 \%)$ \\
\hline & Total & $146(100 \%)$ & $112(100 \%)$ \\
\hline
\end{tabular}

$\mathrm{n}=258$ selective arteriograms of internal pudendal arteries in 126 putients.

"Were repeated with vasoactive substances.

important not to induce full rigidity because of induced reduction of cavernosal artery diameter and flow. Filming takes place at $2,4,6,8,10,11,12,14$, 17 , and $20 \mathrm{sec}$ postinjection. Then the visceral catbeter is replaced by a SIMMONDS (SIM I or II) to selectively catheterize the ipsilateral right hypogastric artery. Films of the right arterial system are taken in the same way, with the opposite projection and placement of the penis on the opposite (left) side. By application of this crossover technique there is no necessity for bilateral femoral puncture as reported in the literature $[1,4,12]$. To avoid superposition by contrast medium in the bladder and to facilitate topographic determination of the urethra, it is useful to insert an indwelling urethral catheter.

\section{Arteriography and Anesthesia}

Though Ginestie and Romieu [1] performed the arteriography during general anesthesia, comparative studies have shown that penile arteries can be best illustrated under epidural anesthesia with the use of vasoactive substances [2]. After establishing criteria of quality (Table 1), 126 bilateral selective arteriograms were judged and correlated with the 


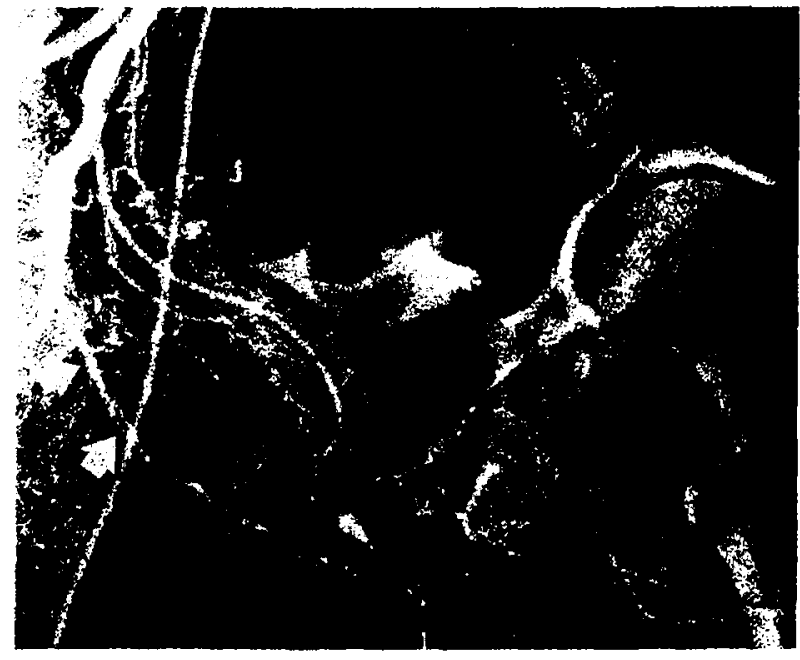

Fig. 3. Selective right arteriogram under general anesthesia without vasoactive drugs. The dorsal artery appears cortuous and there is insufficient dilatation of the cavernosal artery. Interna! pudendal artery (white arrow) and accessory internal pudendal artery (black arrows)

type of anesthesia applied. Image quality after IC injection of vasoactive substances and epidural anesthesia was markedly superior to that performed under local anesthesia only; four angiograms in the latter group had to be repeated under epidural anesthesia. Intraarterial digital subtraction arteriography shows good results when combined with IC injection of vasoactive substances, although there is distinct loss of spatial resolution compared with conventional arteriography; this is partially compensated by improved contrast of the penile arteries. Due to dilution and less amount of contrast medium, there is reduced or no painful reaction or vascular spasms so that epidural anesthesia can be avoided [13].

In general, there is a mild loss of quality by the intraarterial application of vasoactive substances (e.g., phentolamine) when compared with IC application. Moreover, the advantage of penile arterial stretching in a tumescent phase is lost, thus reducing the assessment of peripheral arteriosclerotic lesions.

\section{Potential Problems and Pitfalls in Selective Arteriography}

Incorrect projection, patient malposition, as well as the wrong penile position lead to vascular superimposition, which impairs indentification and interpretation of penile arteries.

By choosing a flow rate of more than $5 \mathrm{ml} / \mathrm{sec}$, marked reflux into the common iliac artery occurs.
The reduced amount of contrast medium is no longer sufficient to demonstrate terminal penile arteries in the late phase with good contrast.

Performance of arteriography without IC injec tion of papaverine-phentolamine leads to insufficient dilatation of pudendal and penile vessels and risks false-positive results. Additionally, the arteries appear tortuous with the penis in flaccid state which makes it difficult to detect arteriosclerotic stenoses (Fig. 3).

By choosing shorter series of exposure, penile arteries can be missed. Under normal conditions they are demonstrated after $10-12 \mathrm{sec}$, and up to 20 sec postinjection when pathologically disturbed.

Superselective catheterization of pudendal internal arteries produces an excellent demonstration of the arterial tree. It is not used, however, because there is a considerable percentage of penile arterial supply via accessory internal pudendal arteries (IPA) coming from other branches of the hypogastric artery.

The application of vasoactive substances in a dose that leads to complete erection with full rigidity is followed by poor visualization of cavernosal arteries. This correlates with the findings of Lue et al. [14] showing late decrease in cavernosal artery flow after full erection induced by IC papaverine.

\section{Normal Anatomy and Variations}

The arterial supply of the penis derives from both internal iliac arteries, predominantly via IPA. The internal iliac artery shows considerable variations in its branching. Most common $(58-65 \%)$ is a separate origin of the superior gluteal artery; the inferior gluteal artery and IPA arise together from the anterior ischiopudendal trunk of the internal iliac artery $[15,16]$. The superior gluteal artery, inferior gluteal artery, and IPA arise separately in 22.5\% [15].

The IPA is the major artery of the erectile organ. As a terminal branch of the internal iliac artery it runs in a curve with an anterior superior concavity in the intrapelvic section at the dorsolateral pelvic wall, remote from the viscera. The IPA enters the lesser pelvis through the small sciatic notch and accompanies the internal pudendal nerve. In its posterior perineal section the IPA enters the ischiorectal fossa where it runs along the inferior insertions of the internal obturator muscle in Alcock's canal [17, 18]. At the dorsal part of the urogenital diaphragm it gives rise to the superficial perineal artery, which goes forward in the ischiobulbous triangle to end at the base of the genitals [18]. Beyond the origin of the superficial perineal artery, the IPA is known as the penile artery. In its anterior perineal section, the 


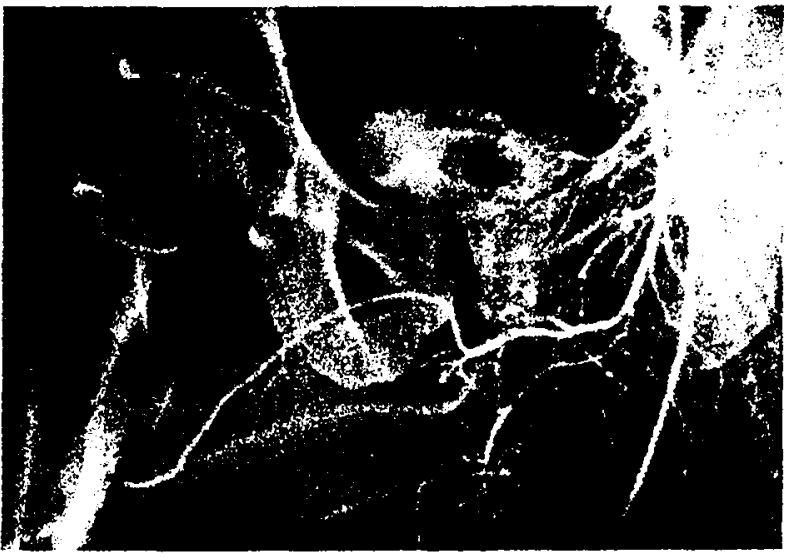

Fig. 4. A 23-year-old patient with primary erectite dysfunction, possibly related to arteriovenous malformation of the pelvis (see Fig. 10). Left anteriogram demonstrates an anatomic variation. with a short proximal cavernosal artery (1) and a distal cavernosal artery coming from the dorsal artery (2). Serial films showed that the colluteral fow via coronal collaterals into the right distal dorsal penile artery (arrow) continued after the injection had terminated. suggesting fow pressures in the right dorsal penile artery secondary to the A.V malformation. or perhaps some proximal obstruction near the root of the penis.

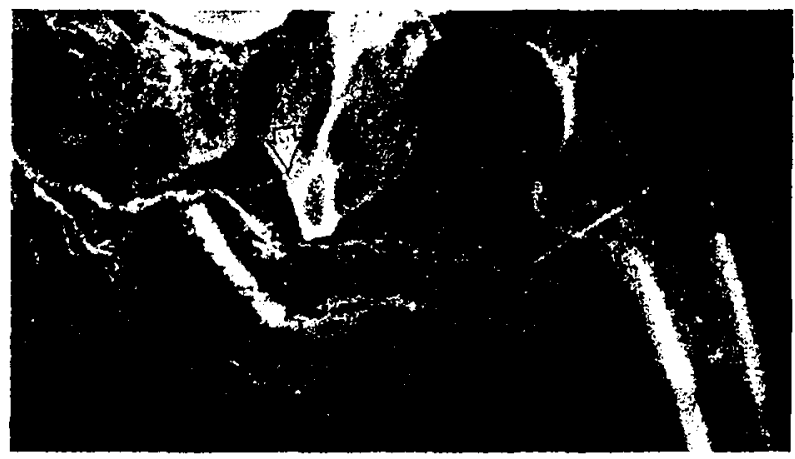

Fig. 5. Nonvascular erectile dysfunction, due to hormone imbalance and loss of libido. A 48 -year-old patient with erectile dysfunction and loss of libido of 3 years duration. There is marked increase of serum estrogen level because of toxic liver disease. Selective arteriogram (epidural anesthesia and vasoactive drugs) shows hypoplasia of dorsal artery (arrows). hemodynamically not relevant. Good visualization of helicine arteries and shunt arteries.

penile artery sends inferior branches-the bulbar artery, the bulbo urethral artery, and the cavernosal artery. The cavernosal artery penetrates the middle aponeurosis and tunica albuginea of the corpus cavernosum [19].

The penile artery terminates in the dorsal penile artery which runs outside the corpus cavernosum on the dorsum of the penis to the glans. There it divides, usually anastomosing with the contralateral dorsal artery and distal branches of the urethral artery (Fig. 4).

The cavernosal artery is functionally of greatest significance for erectile hemodynamics [20]. There is a large individual variability of branching pat-
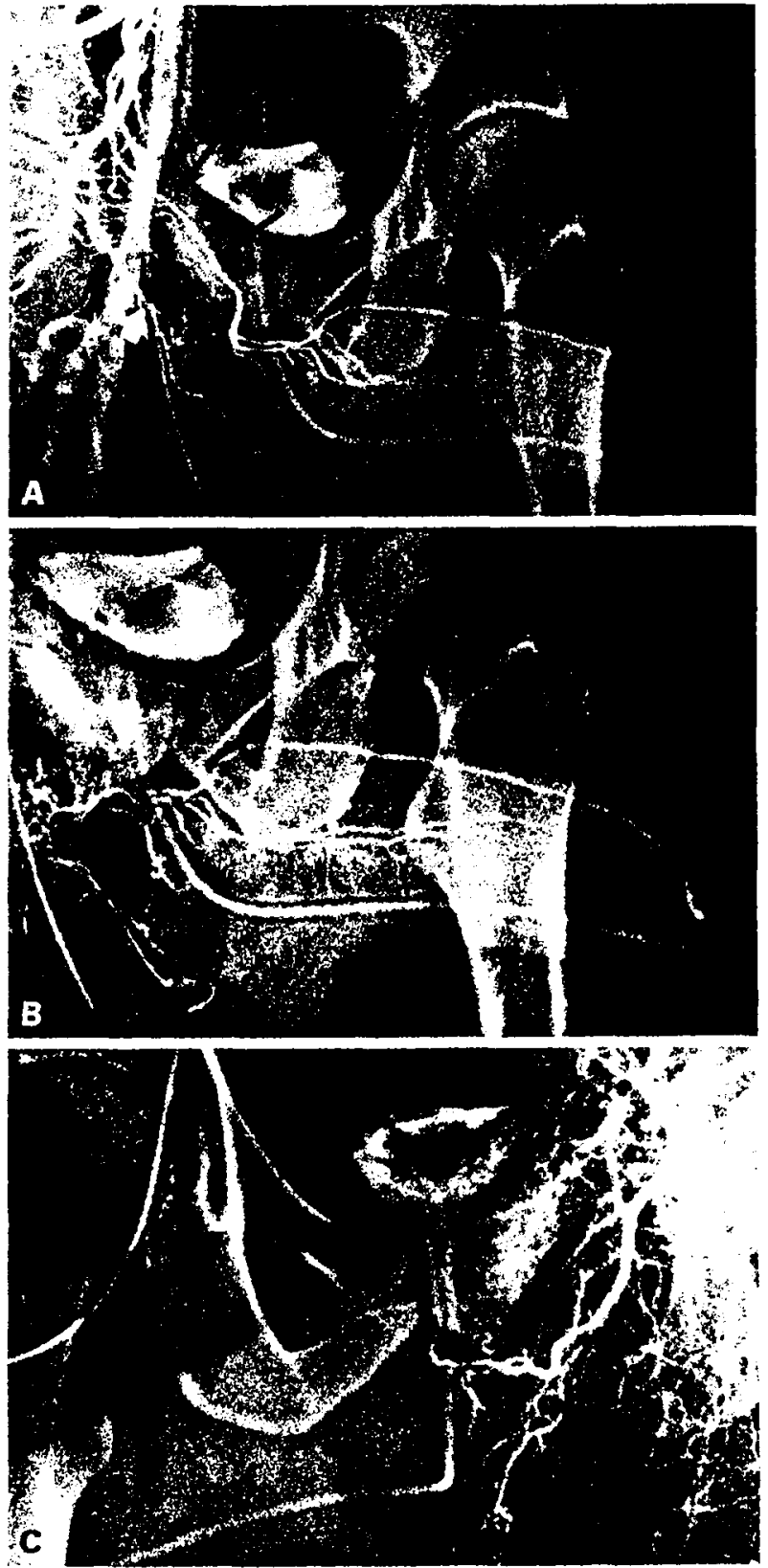

Fig. 6. A 30-year-old patient with incomplete erectile dystunction since adolescence. Selective arteriograms are under epidural anesthesia after intracavernous application of $1 \mathrm{ml}$ papaverinepentolamine mixture A. Right dorsal artery and both cavernosal arteries arise from an accessory internal pudendal artery (black arrows). The internal pudendal (white arrow) artery terminates in the perineal artery. B l.ate phase (17 sec p.i.). The cavernosal arterial system appears like a toothbrush, due to visualization of helicine arteries and shunt arteries to the corpus spongiosum. $\mathbf{C}$ There is hypoplasia of the left dorsal artery and no filling of cavernosal artery.

terns, sites of penetration of the tunica albuginca. and communication with the other penile arteries [21] (Figs. 4-6]. In many cases there is a short proximal retrograde branch to the crus of the corpus cavernosum. En route through the center of the cavernous bodies, the main cavernosal artery sends off numerous helicine arteries which enter the si- 

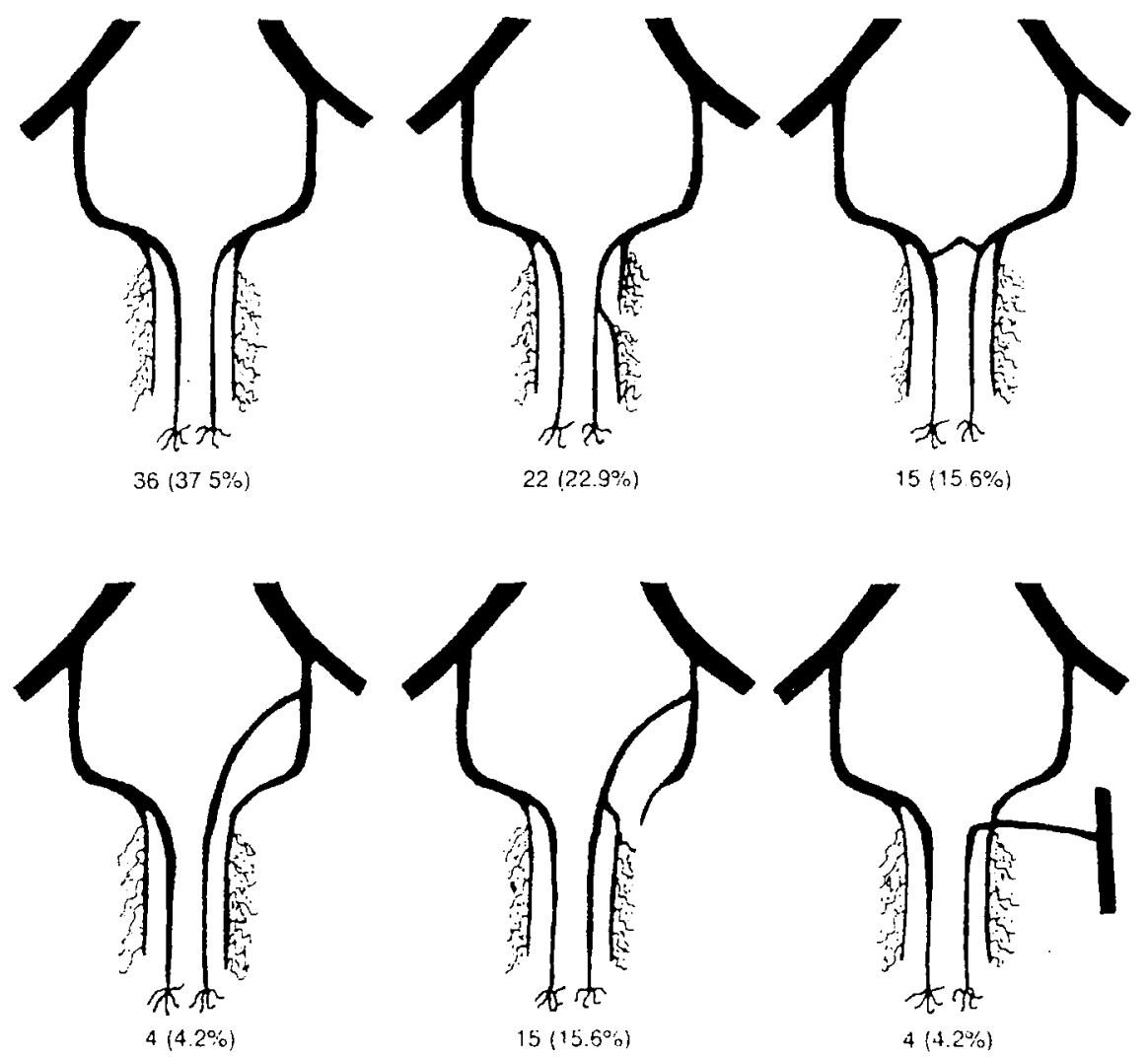

Fig. 7. Normal anatomic variations of penile arterial system and frequency. Ninety-six selective arteriograms in 52 patients that could be considered for anatomical reasons.

nusoidal spaces (Fig. 6). Additionally, several (up to 10 ) anastomoses between the cavernosal artery and the corpus spongiosum can be found in pharmacoangiography (called "shunt" arteries) (Figs. 1, 5).

The dorsal artery of the penis gives superficial branches to the skin as well as deep branches through the tunica albuginea. Helicine-like arteries arising from the dorsal artery cannot be observed arteriographically, although they are described anatomically [22].

Variations of the penile arterial system are common; the most frequent observations are shown in Figure 7. Adachi [23] reported on the occurrence of accessory IPA in $10.9 \%$ of male specimens. Angiographically, this additional artery was described in 6 [16] to $9 \%$ [1] of cases.

We found one or more additional supplying arteries in $10.8 \%$ of patients who did not show arterial malformation [2]. If arteriography revealed penile arterial malformation, this supplementary vessel with its typical appearance and course. occurred in $45 \%$, either unilaterally or bilaterally [2] (Figs. 3,6).

\section{Patients}

From February ' 81 until December ' 86,126 of 469 patients with chronic erectile dysfunction underwent bilateral selective pudendal arteriography af-
Table 2. Arteriographic findings in primary erectile dysfunction (n -.29)

Normal Anatomy

Anatomical variation. hemodynamically irrelevant

Bilateral arterial anomaly

Complex arterial anomaly

Arterio-venous anomaly

ter multidisciplinary evaluation. (Fig. 8) Twentynine patients presented with primary erectile dysfunction (Table 2) and 97 patients with secondary. The mean age was 39 years (19-60 years). Mean duration of erectile dysfunction was 2.5 years.

Since 1984. all the arteriograms were performed after intracavernous application of vasoactive substances. In 14 patients, arteriography was applied in the evaluation of posttraumatic impotence.

\section{Side Effects, Complications, and Contraindications of Selective Arteriography}

Severe stenosis or occlusion of major pelvic vessels, especially involving the origin of IPA, routinely represents a contraindication to selective catheterization unless PTA or thromboendarterectomy of the internal iliac artery seems promising. In 


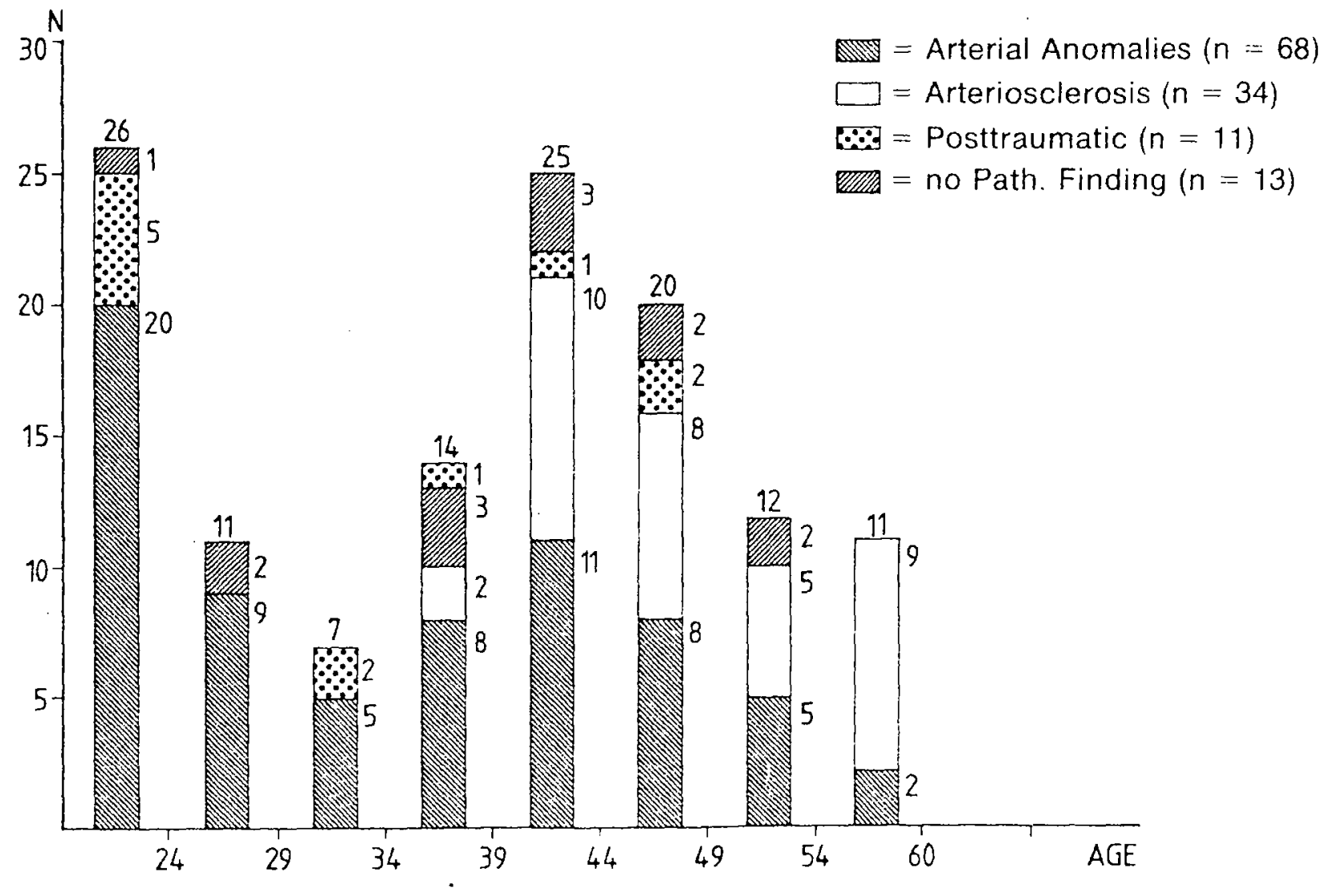

Fig. 8. Arteriographic diagnosis versus age in 126 patients.

these rare cases, selective arteriography should be performed carefully to demonstrate patent distal pudendal arteries.

In 126 arteriographies, we experienced mild allergic reaction with urticaria, nausea, and vomiting in 2 patients. Medium or severe reactions did not occur. In one patient, a local hematoma occurred in the punctured inguinal region; surgical intervention was not required. In more than $50 \%$ of the patients that were investigated under local anesthesia, a painful sensation of heat in the perineal, gluteal, and genital area occurred, lasting for half a minute after selective injection of contrast medium. After intracavernous application of papaverine-phentolamine, no local side effects such as hematoma, infection, or fibrosis were observed. Continuous monitoring of vital functions showed no significant deviation of systolic or diastolic pressure after IC injection of $0.5-1.5 \mathrm{ml}$ of papaverine-phentolamine mixture.

\section{Arteriographic Findings in Primary Erectile Dysfunction}

Primary erectile dysfunction refers to the continuous inability to obtain a sufficient erection from the time of adolescence. Secondary erectile dysfunction refers to the loss of erectile capacity, once achieved.

Of the 469 patients with erectile dysfunction (1981-1987), 55 presented with the clinical symptoms of primary erectile dysfunction. Trauma to the pelvic region, spine, or skull as well as operations or radiation of the pelvis and neurological systemic disease were ruled out. Two patients complained of complete loss of erectile function, 53 had insufficient penile rigidity or shortened period of rigidity or a combination of both, thus precluding sexual intercourse. The mean age was 28.5 years $(19-60$ years). The oldest patient never experienced sufficient erections during 40 years of marriage which was confirmed by his wife. Most patients were 20 25 years of age, and 14 were older than 30 years.

As a result of the standardized multidisciplinary evaluation, two pathogenic factors of impaired erection could be demonstrated in 28 cases, a solitary factor could be isolated in 24 cases, and no organic or psychogenic causes could be found in 3 cases. Impairment of penile arterialization was demonstrated by Doppler and/or selective arteriography in 35 patients $(63.6 \%)$. Avenous etiology, solitary or concomitant, was proven by caverno- 

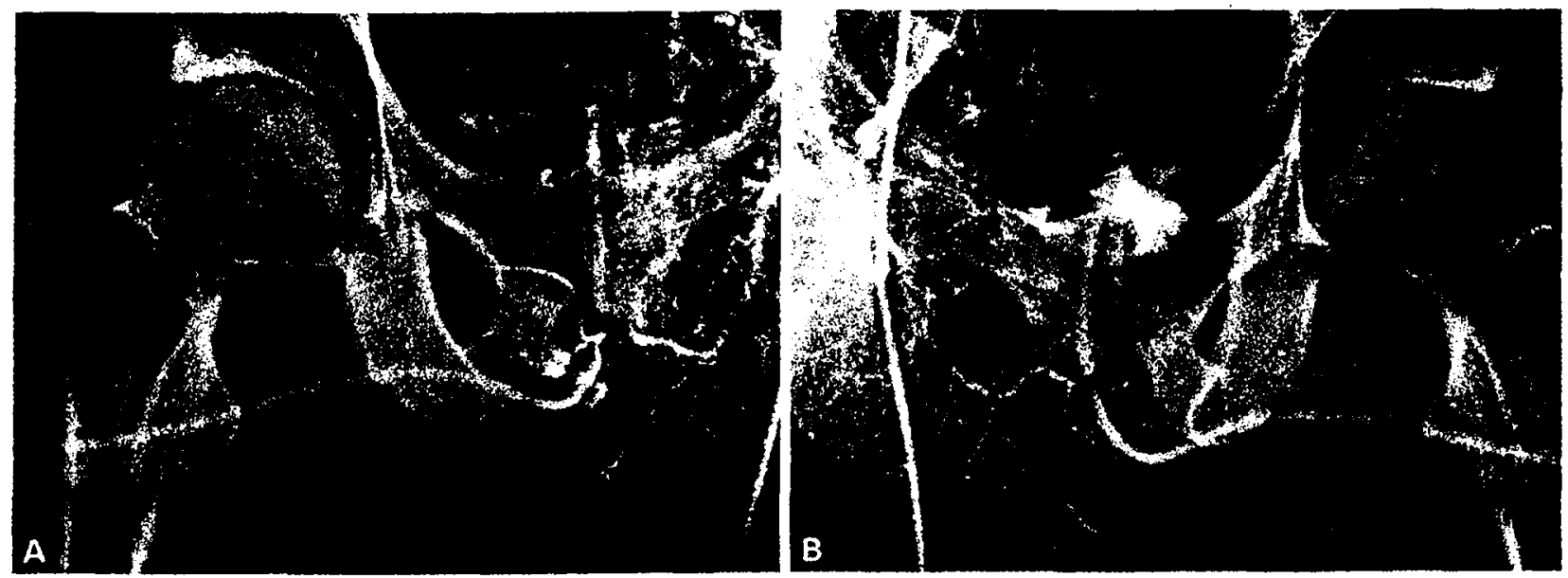

Fig. 9. Vascular erectile dysfunction, pathological inflow due to bilateral hypoplasia of cavernosal arteries in a 27-year-old patient with primary erectile dysfunction. Selective arteriography was done under epidural anesthesia. There is complex arterial malformation. $\mathbf{A}$ 'Two very short proximal cavernosal arteries, arise from the left internal pudendal artery, indicating unilateral hypoplastic cavernosal supply. B There is hypoplasia of the right dorsal artery; no filling of the cavernosal arteries.

sography in 24 patients $[43.6 \%$ ). Even though there were only 10 patients $(18.2 \%)$ with a clear psychogenic factor (psychosexual interview, MMPI, no organic lesions), $\frac{2}{3}$ of the patients in the organic group had severe psychosexual problems secondary to the demonstrated vascular abnormalities.

There were two major groups of causes to be found: (1) a combination of severe arterial anomalies and pathologic venous outfiow in 17 patients, and (2) isolated arterial anomalies in 12 patients.

Based on therapeutic consideration, patients with erectile dysfunction can be categorized into three different groups: nonvascular; vascular, pathologic inflow; or vascular, pathologic outflow. These three groups correspond with the erectile response upon intracavernous injection of vasoactive substances. In 42 patients with primary erectile dysfunction, the final diagnosis could be correlated to the dose of a papaverine-phentolamine combination which was needed to induce a complete erection. In the nonvascular group the mean dosage to achieve full erection was $0.55 \mathrm{ml}$ of the papaverine-phentolamine solution. In all patients with pathologic inflow and without venous leakage, complete erection could be achieved. The mean dose needed was 0.97 $\mathrm{ml}$. In the group with pathologic outflow as the solitary or dominating etiologic factor. 9 patients showed tumescence without rigidity with doses up to $3 \mathrm{ml}$, and 15 patients reached erections with an average of $1.67 \mathrm{ml}$ of vasoactive substances.

Bilateral selective pudendal arteriography was performed to prove a pathological Doppler finding in 29 cases. In 23 of these, a hemodynamically relevant pathologic pattern of penile arterialization was found. 4 patients demonstrated normal penile arterial supply. Two patients revealed a unilateral cavernosal supply not considered hemodynamically relevant in young men without arteriosclerotic risk factors. Bilateral hypoplasia or aplasia of at least two penile arteries was found in 9 patients (Fig. 9). Thirteen patients showed complex arterial anomalies with a mixture of unilateral supply of dorsal and/or cavernosal artery in combination with aplasia or severe hypoplasia regularly involving both axes. The arteriographic findings showed that arterial maldevelopment has to be severe and bilateral in order to cause primary erectile dysfunction on a pure arterial basis. Hypoplasia or aplasia of one dorsal artery is of no significance to erectile function in young men. As reported by Zorgniotti et al. [24], primary erectile dysfunction can be associated with pudendal arteriovenous malformation. It seems to be a rare cause for erectile failure and was found in one of our patients with primary erectile failure (Figs. 4, 10).

\section{Penile Arterial Malformation in Secondary Erectile Dysfunction}

Current arteriographic reports primarily describe arteriosclerotic lesions as a cause of vascular crectile dysfunction $[1,4,5,12,25-27]$. A comprehensive description or classification of penile arterial anomalies does not exist. Aplasia and hypoplasia of penile arteries were reported by Ginestie and Romieu [1] as a cause for primary erectile dysfunction. Michal, one of the first to establish modern diagnosis of erectile dysfunction and pioneer of revascularization surgery, described the occurrence of aplasia or hypoplasia of cavernosal artery and correlated it with "constitutional" impotence [4]. 

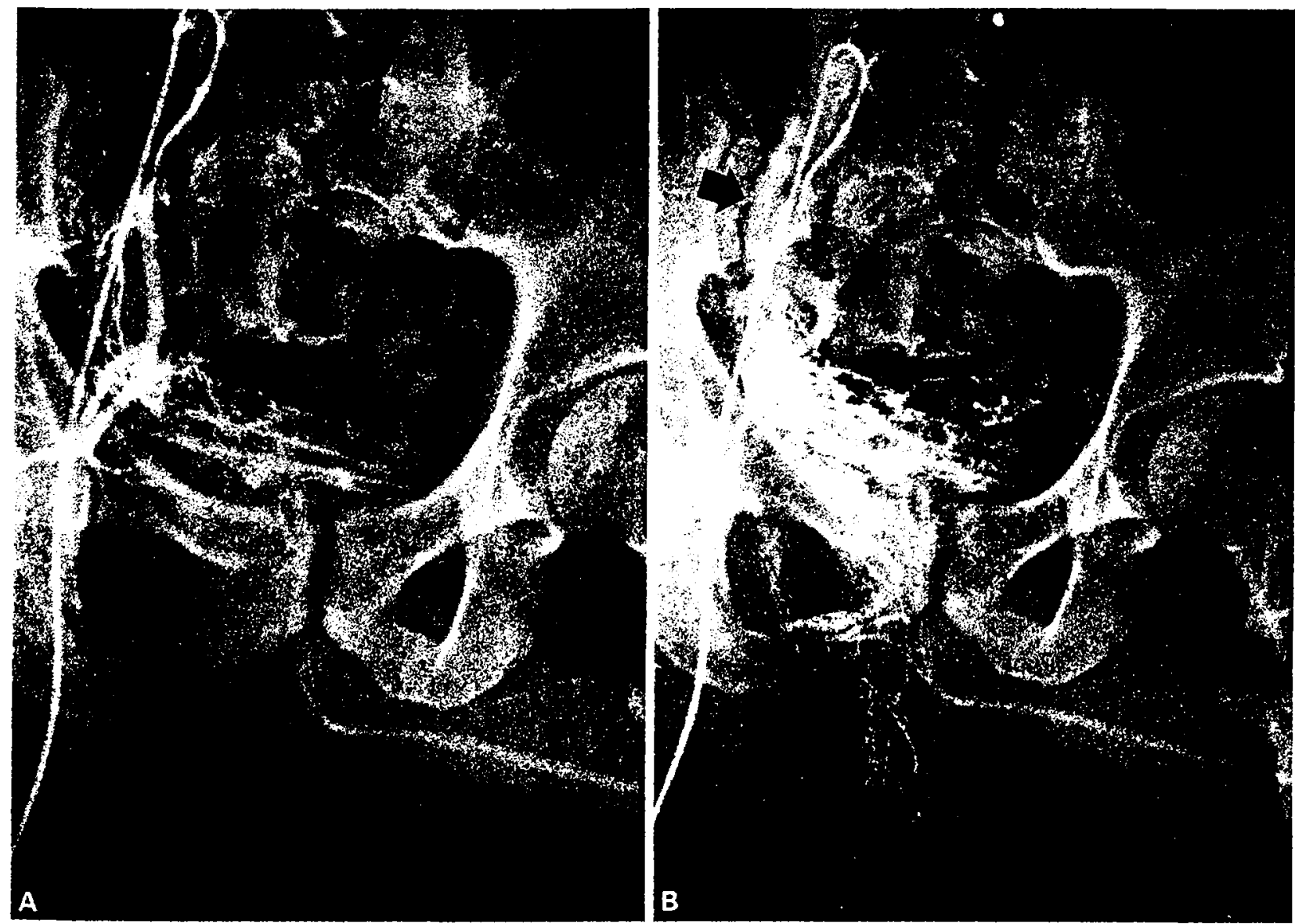

Fig. 10. Vascular erectile dysfunction, pathological inflow due to vascular malformation (same case as Fig. 4). A There is arteriovenous malformation with arterial supply from superior gluteal, internal pudendal, and one vesical artery. B Note massive venous opacification of common and internal iliac veins (arrow). No penile arteries are demonstrated in the late phase.

Table 3. Classification of penile arterial anomalies

\begin{tabular}{|c|c|c|}
\hline & $N$ & $\begin{array}{l}\text { Plimary } \\
\text { erectile } \\
\text { dysfunction }\end{array}$ \\
\hline \multicolumn{3}{|l|}{ Unilateral anomaly } \\
\hline $\begin{array}{l}\text { Hypoplasia or aplasia of one penile } \\
\text { artery }\end{array}$ & 5 & - \\
\hline $\begin{array}{l}\text { Hypoplatsia or aplasia of two penile } \\
\text { arteries }\end{array}$ & 4 & - \\
\hline Unilateral cavernosal supply & 17 & 2 \\
\hline \multicolumn{3}{|l|}{ Bilateral anomaly } \\
\hline Bilateral hypo-or aplasia & 18 & 9 \\
\hline Complex anomaly & 23 & 13 \\
\hline Arteriovenous mallormation & $\mathbf{I}$ & I \\
\hline
\end{tabular}

The basic problem in the assessment of abnormal penile arterialization is to find a correlation between the number, caliber, and wallstructure of the penile arterial system and the extent of the associated functional impairment (Table 3, Fig. 11). There is no animal experimental model because of numerous variant parameters: age and risk factors of arteriosclerosis; size of penis in flaccid and erect state: high variability of inter-arterial anastomoses: incomplete knowledge of the distribution of blood in penile arteries; gradually different appearance of erectile dysfunction; and other relevant factors (e.g., neural, hormonal, metabolic, venous). Our conclusions about the impact of arterial malformation are derived from the study of a group with primary erectile dysfunction due to isolated arterial genesis and a control group of normally potent young men $(n=30)$ investigated by detailed Doppler examination [2]:

Deviations from the paired penile supply (two dorsal arteries and two cavernosal arteries) frequently occur. Only $50 \%$ of the normally potent showed an anatomically normal arterial pattern.

Unilateral hypoplasia or aplasia of a dorsal artery could be demonstrated in $30 \%$ of the volunteers.

Unilateral hypoplasia of both penile arteries does not lead to primary erectile dysfunction. De- 
UNILATERAL HYPOPLASIA OR APLASIA OF PENILE ARTERIES THAT DO NOT CAUSE PRIMARY ERECTILE DYSFUNCTION
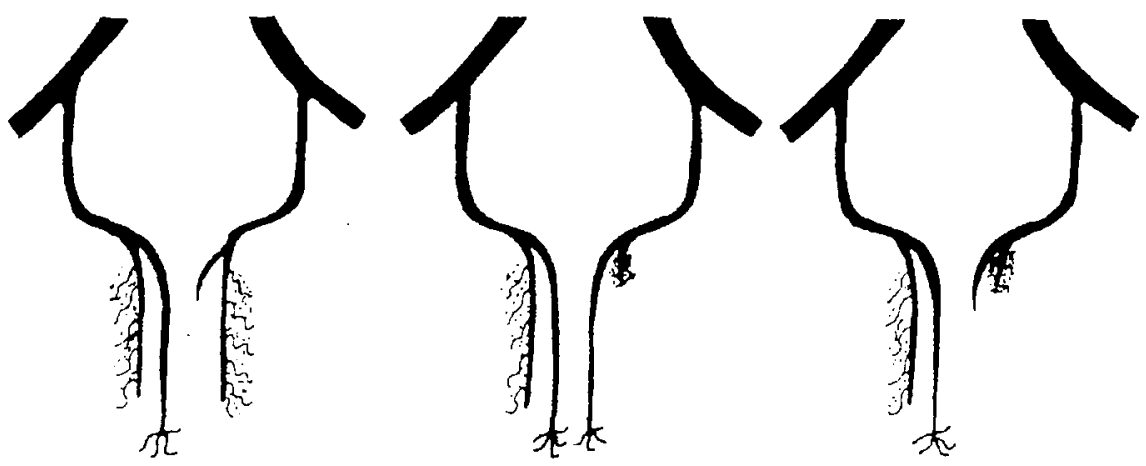

UNILATERAL SUPPLY ONLY VERY RARELY CAUSING PRIMARY ERECTILE DYSFUNCTION
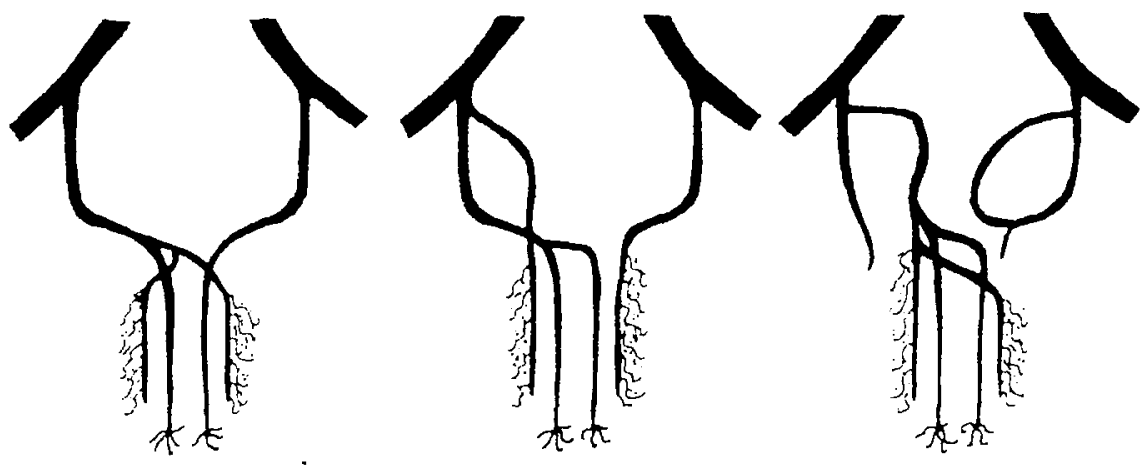

BILATERAL HYPO- OR APLASIA FREOUENTLYY CAUSING PRIMARY ERECTIIE DYSFUNCTION
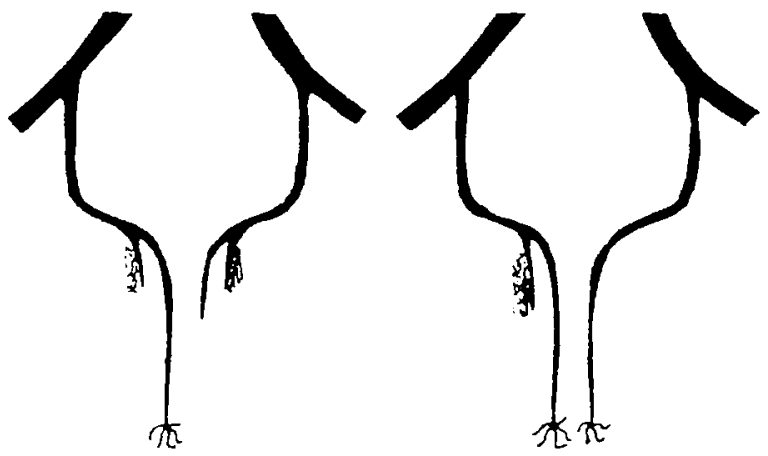

COMPLEX ANOMALIES FREQUENTLY CAUSING PRIMARY ERECTILE DYSFUNCTION

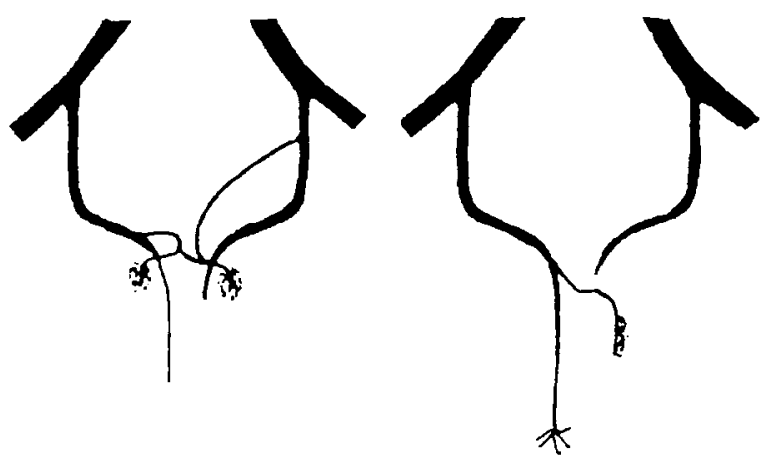

Fig. 11. Schematic drawing of penile arterial anomalies. 
pending on the extent of hypoplasia, age, and risk factors of arteriosclerosis, hypoplasia can be a cause of secondary failure.

Bilateral aplasia or hypoplasia or complex anomalies involving the cavernosal arteries represent the essential condition for primary erectile dysfunction.

Unilateral supply of dorsal arteries can be defined as a variant of normal; unilateral supply of the cavernosal arteries or the whole penile arterial bed does not cause erectile dysfunction, but may predispose to secondary erectile dysfunction. The onset of erectile dysfunction is influenced by age and risk factors of arteriosclerosis.

Penile arterial anomalies often are combined with pathologic outflow conditions. It remains to be determined whether lack of cavernosal compliance, insufficient inflow, or pathologic drainage is responsible for the venous insufficiency.

With continuous aging, all the arteries show typical changes, with a large increase of nonelastic fibrous tissue and diminished elastic content [28]. This leads to reduction of arterial compliance with increasing age. Thus, in cases of unilateral cavernosal supply, the loss of $50 \%$ inflow by the missing pudendal artery can be compensated by the contralateral side for many years. This vasomotor erectile reserve becomes progressively reduced with increasing age, and more importantly, when risk factors of arteriosclerosis are present.

\section{Postraumatic Erectile Dysfunction}

Fourteen patients with posttraumatic erectile dysfunction were examined. All had normal sexual function before the traumatic event. Mean age was 31.3 , ranging from 22 to 49 years. Selective pudendal arteriography was performed in addition to the multidisciplinary investigations in these patients. Neurologic disease was assessed by neurologic examination, neurophysiologic tests (BCR-latency measurement, SSEP, and in a few cases, topographic brain mapping TBM) and/or cystometry. Eleven of the 14 patients showed severe pelvic bone trauma, in each case involving the anterior pelvic girdle. Complete or incomplete rupture of the prostatomembranous urethra was present in 8 patients: In 3 cases, direct trauma had caused injury to the penile root. Fracture of the vertebral column was present in 1 , and head injuries were found in 2 patients.

\section{Arteriographic Findings in Posttraumatic Erectile Dysfunction}

Pathologic changes in the pudendal-penile territory could be demonstrated in 11 patients, which in itself
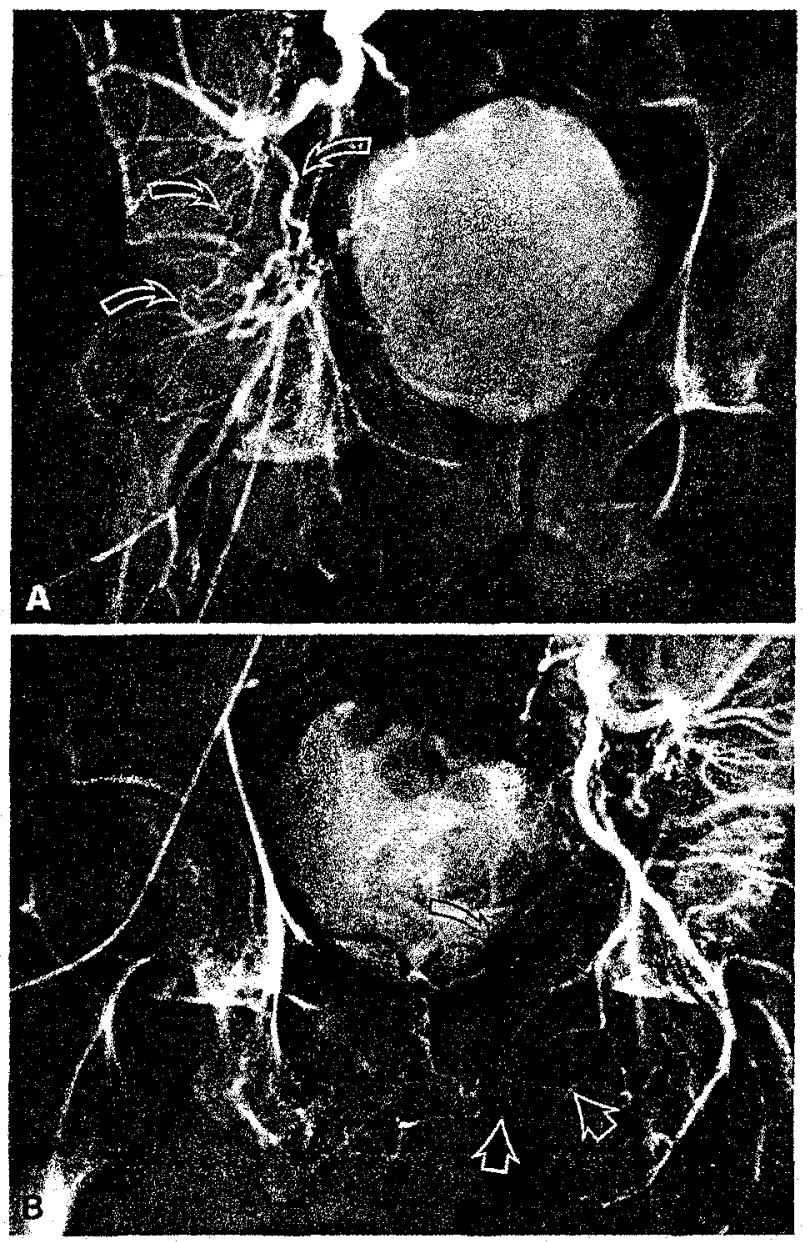

Fig. 12. A 22-year-old patient with posttraumatic erectile failure after fracture of the pelvis. Arteriography under epidural anesthesia with $1.5 \mathrm{ml}$ of vasoactive drugs. A There is complete rupture of the ischiopudendal trunk with collaterals (arrows) from superior gluteal artery. Pudendal and penile vessels are not opacified on the right side. B Note occlusion of the left internal pudendal artery at the level of the urogenital diaphragm (white arrows). Small penile vessels are opacified via collateral arterialization (black arrows).

explained the erectile impairment. Additional injury to the aortoiliac region was found in 3 patients ( Fig. 12). The most frequent vascular changes were observed in the distal internal pudendal artery at the level of the urogenital diaphragm (Fig. 13). Eight arteriograms showed an arrest of the column of contrast medium in the vessel and in 3 cases the more distal portions could be visualized by collateral circulation. Five of the 8 patients with rupture of the urethra had bilateral vascular obstruction at the level of the distal IPA. Two patients also had venogenic impotence, alone or in combination with arterial obstruction.

In one patient with rupture of the urethra, fracture of the pelvic girdle, and perforation of the perineum, both IPA arteries were normal. As a result of direct trauma to the penis (penile fracture), there 

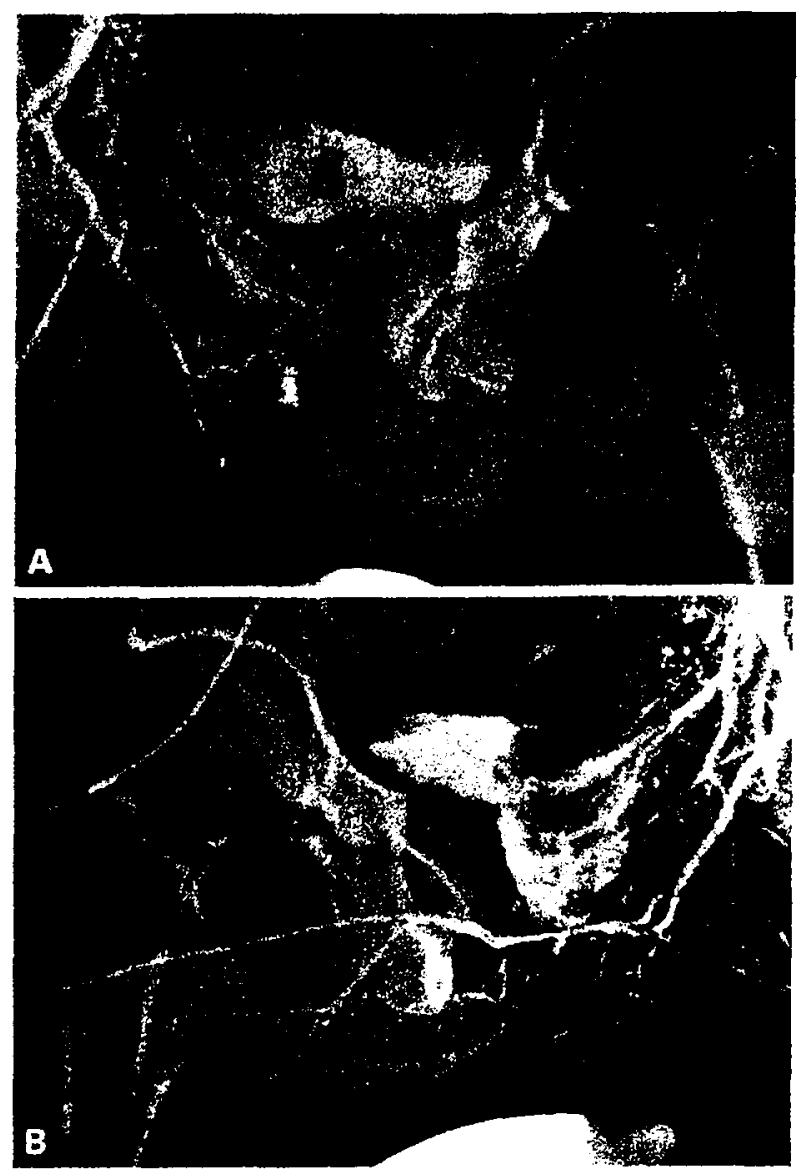

Fig. 13. A 22-year-old patient with posttraumatic erectile dysfunction after fracture of the anterior pelvis girdle and urethral rupture. Arteriography was performed under epidural anesthesia with $0.5 \mathrm{ml}$ vasoactive drugs. A Except for the artery to the bulb. there is no opacification of the penile arteries on the right side. $B$ Note obstruction of the proximal cavernosal arteries at the level of the urogenital diaphragm (arrows) There is unitateral cavernosal supply; retrograde filling is via an anastomosis from the dorsal artery.

was an obstruction of the dorsal artery and the cavernosal artery in the middle penile portion without opacification of the middle and distal segments of the corpus cavernosum (Fig. 14).

Due to their proximate location, the penile nerves and arteries are frequently injured in association with injury to urethrea or urogenital diaphragm. Noniatrogenic injuries are caused by blunt or perforating trauma to the abdomen, pelvis, and perineum as well as external genitalia. Characteristic fractures that result in injury to the lower urinary tract are single or multiple fractures of the ischiopubic ramus and the symphysis. About 5-10\% of the pelvic fractures are accompanied by injuries of the lower urinary tract $[29,30]$.

Injury to the urethra and the accompanying nerves and vessels is caused by a shearing mechanism. Because of the extremely mobile fragments of the fractured pelvic girdle and the puboprostatic lig- aments, the energy of the trauma is transmitted to the anatomical structures attached to the urogenital diaphragm [31]. There is disagreement in the literature on whether, in connection with the pelvic trauma, the erectile dysfunction occurs because of the injury itself or secondary to the surgical treatment of urethral injury or a symphysial rupture [3234]. More recent studies show that the treatment of injuries to the prostatomembranous urethra by means of conservative cystostomy and secondary urethroplasty is associated with a considerably lower rate of impotence [32, 33] from a primary surgical repair $[35,36]$. The overall incidence of erectile impotence following primary surgical intervention is $44.3 \%$, whereas primary conservative therapy with urethroplasty performed at a later date led to erectile dysfunction in only $4.2 \%$ of the patients [37].

A multidisciplinary evaluation of our 14 patients showed that the vascular lesions-occurring alone or in combination with neurogenic damage-should be primarily considered in the pathogenesis of posttraumatic erectile dysfunction. This is even more important because, due to the development and improvement in vascular surgery in the last 5 years $[38,39]$, revascularization can be offered to all those patients who do not show any additional neurogenic etiology.

In patients with mixed arterial and neurogenic disorder, a semiconservative therapy with injection of papaverine-phentolamine is indicated $[40,41]$.

Seven of our 14 patients with posttraumatic erectile dysfunction perform the corpus cavernosum-autoinjection therapy successtully.

\section{Occlusive Arterial Disease in Aorta and Iliac Arteries}

In 1923, Leriche described a syndrome related to thrombotic obliteration of the aortic bifurcation [42]. As a rule, patients are young adults who complain of the following symptoms [43]: inability to keep a stable erection, fatigue of both lower limbs, global atrophy of both lower limbs, no trophic changes, wounds heal either very sluggishly or not at all, and pallor of the legs and feet. Clinical investigation reveals absent pulses of the legs or groins. The pulse of the aorta can be palpated only above the umbilicus.

When loss of penile rigidity is due to occlusive arterial disease in the aortoiliac area, the penile arterial insufficiency precedes the symptoms of arterial insufficiency of the legs in $30 \%$ of the cases [44]. In a consecutive series of 98 men admitted for evaluation of arteriosclerotic disease in the leg, 70 had aortoiliac occlusions, $39(58 \%)$ of which complained about erectile dysfunction [44]. Nath et al. [45], 

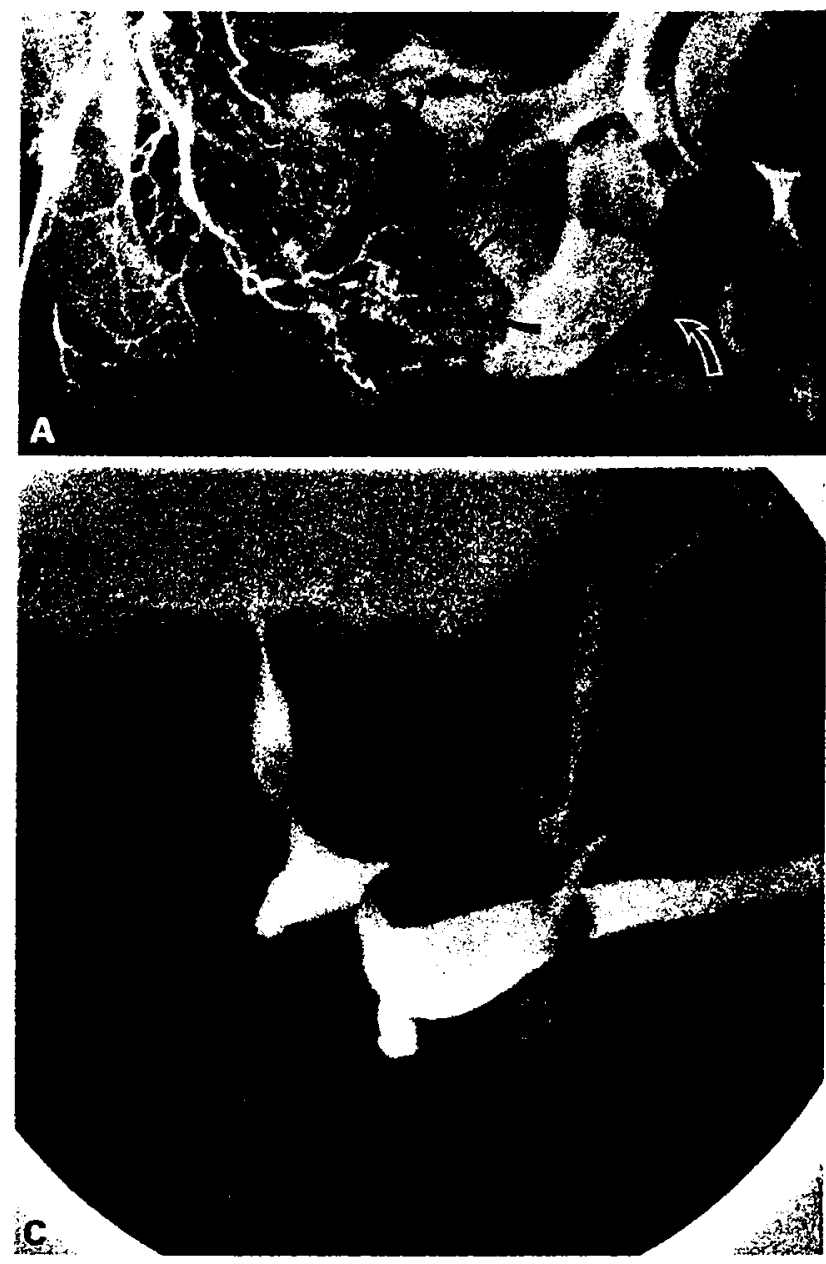

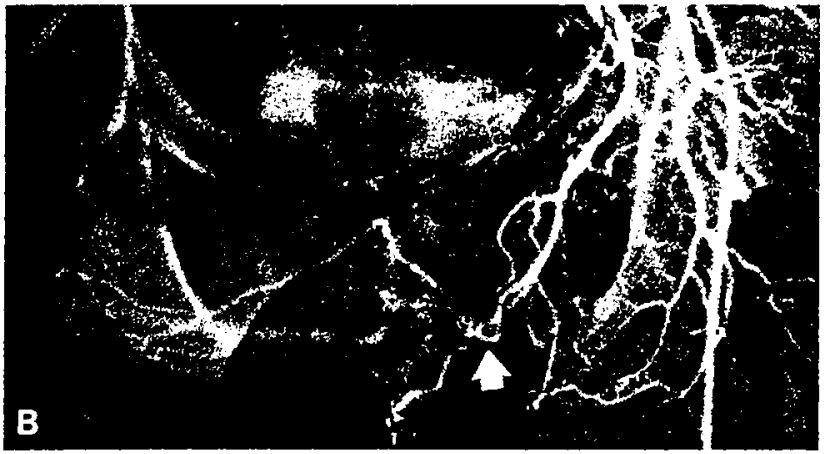

Fig. 14. A 33-year-old patient with posttraumatic erectile dysfunction and ejaculatory disorder after straddle injury. There is a fracture of the anterior pelvic girdle and a urethral rupture. Arteriography was performed under epidural anesthesia: no vasoactive drugs. A Right side shows partial obstruction of the internal pudendal artery with the collateral artery (large black arrow). The dorsal and cavernosal artery form from the middle penile portion (small black arrows). Collateral artery to opposite dorsal artery (white arrow). B Left side: coiling and partial obstruction of the internal pudendal artery at the level of the urogenital dia. phragm (arrow). C Retrograde urethrogram-showing the urethral injury.
Queral et al. [46], and DePalma et al. [47] reported incidence of erectile dysfunction in $71-81 \%$ of patients in whom aortoiliac reconstructive surgery was indicated. According to Metz and Herning [44], the loss of penile rigidity could be due primarily to a rapid decrease of the arterial pressure in the pudendal-penile area caused by a dilatation of the artcrial bed distal to a stenosis or occlusion.

In another study, $8 \%$ of aneurysm patients and $70 \%$ of patients with aortoiliac obstruction had preoperative impairment of erection. After operation, further impairment of erection developed in $21 \%$ of sexually normal patients having aneurysmectomy and in $34 \%$ of normal patients having revascularization of occlusive disease [48]. In patients with aortoiliac disease, the penile noninvasive studies do not allow evaluation of concomitant distal penile arterial disease. The selective arteriographic examination in our group of patients with arteriosclerotic lesions $(n=34)$ demonstrated that more than $60 \%$ of patients with moderate aortoiliac lesions (stenoses) also had occlusions and hemodynami- cally significant stenoses distally in the internal pudendal and penile arteries [2].

In patients who develop impotence following aortoiliac reconstructive vascular surgery $[44,46$, 48-51] several possible causes exist which are difficult to distinguish: preexisting distal arteriosclerosis, inadequate central restoration of blood flow, surgical interference with the autonomic nervous system. and concomitant venogenic impotence.

Some authors $[52,53]$ conclude that surgical intervention tends to further impair erectile function, but Sabri and Cotton [54] and Michal et al. [55] reported significant improvement in prospective studies. They especially were interested in preservation of the integrity of the hypogastric plexus by increased use of thromboendarterectomy to the internal iliac arteries.

A special constellation of occlusive arteriosclerosis of the aortoiliac vessels can cause a syndrome consisting of inability to maintain the erection after initiation of strenuous coital movements. The syndrome is thought to be due to a redistribution of a 
limited blood flow in favor of the activated muscles and is therefore named the "pelvic steal syndrome" (PSS) or "external iliac steal syndrome" $[48,56,57]$ analogous to the subclavian-steal-syndrome.

PSS can be suggested if two of the following three criteria are fulfilled [58]: appropriate clinical symptoms, a $25 \%$ drop in the penile-brachial pressure-index (PBPI) after exercise. and arteriographic evidence of large collateral channels between the pelvic area and the lower limbs.

\section{Arteriosclerosis of Internal Pudendal Arteries and Penile Vessels}

The changes in morphology and structure of pudendal-penile arteries are age related and correspond to arteriosclerotic alterations in other vascular regions [59]. The dramatic circulatory events of penile erection require sufficient elasticity and compliance of supplying arteries, as well as cavernosal structures [20]. If arteriosclerosis reduces cavernosal arterialization, collateral connections are adequate to maintain organ viability. The functional increase in arterial inflow, however, becomes insufficient to produce intracavernosal pressure adequate for full erection [60] and progressive erectile dysfunction develops.

Erectile dysfunction itself may represent an index of beginning generalized arteriosclerosis comparable to angina pectoris. In the same manner as in coronary heart disease, risk factors of arteriosclerosis-diabetes mellitus, hypertension, cigarette smoking, and hyperlipidemia-lead to arteriosclerotic manifestations at a younger age [61,62]. This became evident in our patient group with arteriographically proven peripheral arteriosclerotic lesions $(n=34)$ with a mean age of 46 years: all but one patient showed at least one risk factor. 27 showed two or more risk factors. Eighty-two\% were heavy smokers, $63 \%$ showed hyperlipidemia, $44 \%$ had diabetis mellitus, and $11 \%$ presented with hypertension.

It has been shown that coincidental risk factors increase the rate of organic erectile dysfunction up to $90 \%$ [63]. Virag [63] concluded that $10 \%$ of the men between 40 and 60 years can expect to suffer from erectile dysfunction. At least $60 \%$ of these men will experience erectile dysfunction of organic nature, with vascular causes in $\frac{2}{3}$ of them [63]. The studies that include selective arteriography in the diagnostic workup of impotent patients $[4,25,26]$ revealed a vascular etiology in up to $85.5 \%$ [4].

The arteriographic appearance of obstructed peripheral arteries in erectile dysfunction is rather uniform [4, 25]. Stenoses and occlusions are most frequently situated bilaterally at the terminal part of

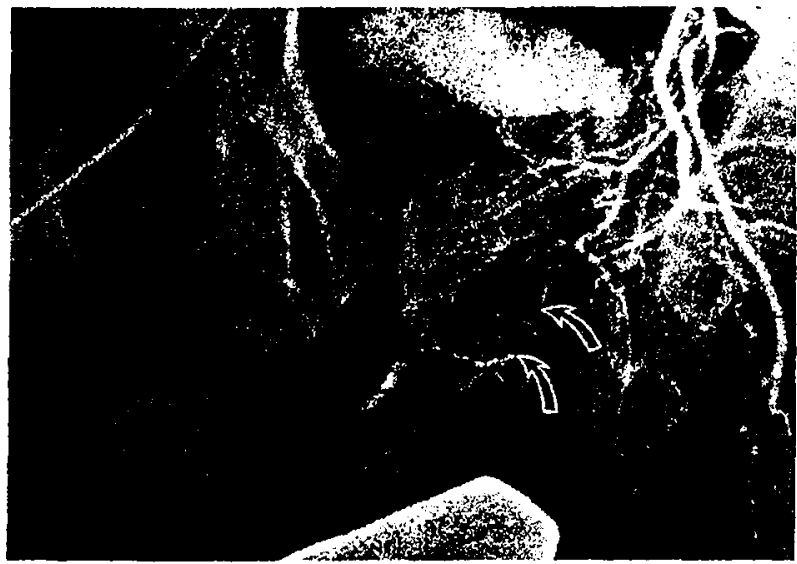

Fig. 15. A 45-year-old patient with complete loss of erectile dysfunction for 4 years due to arterial disease. He was a heavy smoker and had hyperlipidemia. Arteriography was performed under epidural anesthesia with $1.0 \mathrm{~m}$ l of vasoactive drugs. There is atherosclerotic obstruction of the internal pudendal artery (arrows), collateral filling of the terminal internal pudendal artery with artery of the buib. and obstruction of dorsal and cavernosial arteries. Stenoses and occlusions were also present on the right.

the IPA at the level of the urogenital diaphragm. In these cases the artery of the bulb can usually still be visualized because of its further proximal branching, whereas the dorsal and cavernosal arteries are often completely obstructed. Only poor collateralization can be found in these cases (Fig. 15). Segmental stenoses alone or in combination with obstruction and partly effective collateralization can be observed in the IPA before and during its course in Alcock's canal. Isolated stenosis at its origin from the ischiopudendal trunk can also occur.

\section{References}

1. Ginestie JF, Romieu A (1976) L'exploration radiologique de l'impuissance, Malonie SA, Paris, pp 2-24

2. Bähren W (1985) Erektile Dysfunktion: Selektive arteriographische Diagnostik und Therapie unter Anwendung vasoaktiver Substanzen. Habilitationsschrift Ulm, pp 126-130

3. Bookstein JJ, Valji K. Parsons L, Kessler W (1987) Pharmacoarteriography in the evaluation of impotence. J Urol 137:333-337

4. Michal V, Kovac J, Belan A (1984) Arterial lesions in impotence: Phalloarteriography. Inter Angio 3:247-254

5. Michal V, Pospichal J (1978) Phalloarteriography in the diagnosis of erectile impotence. World J Surg 2:239-248

6. Bähren W, Stief CG, Scherb W, Gall H. Gallwitz A, Altwein JE (1986) Rationelle Diagnostik der erektilen Dystunktion unter Anwendung eines pharmakologischen Testes. Akt Urologie 4:177-180

7. Furlow WL, (1986) Diagnostic protocol for patient selection-penile revascularization versus prosthesis implantation. ISIR (edt): Proc H World Meeting on Impotence. (abstract 13.3a) Prag

8. Castaneda-Zuniga WR, Smith A, Kaye K, Rusnak B, Herrerra M, Miller R. Amplatz K. Weens C, Ketchum D (1982) 
Transluminal angioplasty for treatment of vasculogenic impotence. AJR 139:371-373

9. Van Unnik JG, Marsman IW (1984) Impotence due to the external iliac steal syndrome treated by percutaneous transluminal angioplasty. J Urol 131:544-545

10. Goldstein I (1986) Revascularization procedures. Seminars in urology-impotence, vol IV, 4:252-258

11. Lue T, Tanagho EA (1985) Diagnostische Abklärung der erektilen Impotenz. Akt Urol J6:244-249

12. Zorgniotti AW, Padula G. Shaw WW (1983) Selective arteriography for vascular impotence. World J Urol 1:213-217

13. Leipner N, Porst H, Köster O, Nadstawek J (1986) DSA und konventionelle Angiographie im Vergleich bei der angiographischen Diagnostik der Impotentia coeundi. Fortschr Röntgenstr 144, 5:516-522

14. Lue TF, Hricak H, Marich KW, Tanagho EA (1985) Vasculogenic impotence evaluated by high-resolution ultrasonography and pulsed Doppler spectrum analysis. Radiology 155:777-781

15. Braithwaite JL (1952) Variations in origin of the parietal branches of the internal iliac artery. J Anat 86:423-430

16. Huguet JF, Clerissi J, Juhan C (1981) Radiologic anatomy of pudendal artery. Eur J Radiol 1:278-284

17. Gray H (1973) Gray's Anatomy of the Human Body. Gross CM (ed) Lea and Febinger, Philadelphia, p 648

18. Langer $C$ (1862) Über das Gefaßßsystem der männlichen Schwellorgane. S Ber Akad Wiss Wien Math naturw KI $46: 120-129$

19. Müller J (1835) Entdeckung der bei der Erektion wirksamen Arterien. Arch Anat: 202-213

20. Lue TF, Jünemann KP, Fournier GR, Tanagho EA (1986) Mechanism of penile erection. ISIR (edt): Proc 2nd World Meeting on Impotence (abstract 1.1) Prag

21. Forster A (1903) Beiträge zur Anatomie der äußeren männlichen Geschlechtsorgane des Menschen: Z J Morphol u Antrhopol Bd 6:435-501

22. Stieve H (1930) Männliche Genitalorgane. Hdb mikrosk Anat d Menschen 7:2

23. Adachi B (1927) Das Arteriensystem der Japaner: Bd II Supp ad Acta scholae medicinalis universitatis imperialis Kyoto $9.95-125$

24. Zorgniotti AW, Shaw WW, Padula G, Rossi G (1984) Impotence associated with pudendal arteriovenous malformation. J Urol 132:128-131

25. Gray R, Keresteci A, St. Louis E, Grosman H, Jewett M Rankin J, Provan J (1982) Investigation of impotence by internal pudendal angiography: Experience with 73 cases. Radiology 144:773-780

26. Juhan CM. Huguet JF, Clerissi JA, Courjaret P (1980) Classification of internal pudendal artery lesions in one-hundred cases. In Zorgniotti AW, Rossi G (eds): Vasculogenic impotence. Thomas, Springfield, pp $153-169$

27. Struyven J, Gregoir W, Giannakopoulos X. Wauters E (1979) Selective pudendal arteriography. Eur Urol 5:233-242

28. Ahmed MM (1967) Age and sex differences in the structure of the tunica media of the human aorta. Acta Anat 66:45-53

29. Hartmann K (1955) Blasen-und Harniöhrenverletzungen bei Beckenbrüchen. Langenbecks Archiv Klin Chir 282:943-949

30. Sigel A, Chlepas S (1981) Verletzungen der Harnröhre. In: Lutzeyer, W (ed): Traumatologie des Urogenitaltraktes. Springer Verlag, Berlin, Heidelberg, New York, pp 131-199

31. Mitchell JP (1968) Injuries to the urethra. Br J Urol 40:649654

32. Coffield KS, Weems WL (1977) Experience with management of posterior urethral injury associated with pelvic tracture. J Urol 117:723-725

33. Morehouse DP, McKinon KJ (1980) Management of prostatomembranous urethral disruption. 13 years experience. $J$ Urol 123:173-178

34. Pierce JM (1972) Primary reconstruction of the disrupted urethra. In: Scott R (ed): Current controversies. Saunders. Philadelphia, pp 139-143

35. Gibson GR (1974) Urological management and complicat- tions of fractured pelvis and ruptured urethra. J Urol 111:353-356

36. Jackson DH, Williams JC (1974) Urethral injury: A retrospective study. Br J Urol 46:665-671

37. Sharlip JD (1981) Penile arteriography in impotence after pelvic trauma. J Urol 126:477-481

38. Hauri D (1984) Vascular reconstruction. Read at Symposium: Controversy in the diagnosis and treatment of erectile impotence, Nov 30-Dec 1, 1984, Leiden, The Netherlands

39. Virag $R$ (1984) The treatment of angiogenic impotence. Inter Angio 3:275-280

40. Stief CG, Bähren W, Gall H, Scherb W, Gallwitz A, Altwein JE (1986) Schwellkörper-Autoinjektionstherapie (SKAT): erste Erfahrungen bei erektiler Dysfunktion. Urologe A $25: 63-66$

41. Zorgniotti AW, Lefleur RS (1985) Auto-injection of the corpus cavernosum with a vasoactive drug combination for vasculogenic impotence. J Urol 133:39-41

42. Leriche R (1923) Desobliterations arterielles hautes comme cause d'une insuffisance circulatoire des membres inferieurs. Bull Soc Chirurgie 49:1404-1406

43. Leriche R, Morel A (1948) The syndrome of thrombotic obliteration of the aortic bifurcation. Ann Surg 127:193-206

44. Metz P, Herning M (1984) Impotence and aorto-iliac disease with special reference to the pelvic steal syndrome. Inter Angio 3:259-262

45. Nath RL, Menzoian JO, Kaplan KH, McMillian TN, Siroky MB, Krane RJ (1981) The multidisciplinary approach to vasculogenic impotence. Surgery 89, 1:124-133

46. Queral LA, Whitehouse WM, Flinn WR, Zarins CK, Bergan JJ. Yao JS (1979) Pelvic hemodynamics after aortoiliac reconsiruction. Surgery $86,6: 799-808$

47. De Paima RG, Levine SB, Feldman S (1978) Preservation of erectile function after aorto-iliac reconstruction. Arch Surg 113:958-962

48. May AG, De Weese JA, Rob CG (1969) Changes in sexual function following operation on the abdominal aorta. Surgery $65,1: 41-47$

49. Kholoussy AM, Gain T, Matsumoto T (1981) lmpotence after aorto-iliac surgery: Current concepts. Angiology 32, 9:589-594

50. Michal V, Kramar R. Highal L, First P (1980) Aortoiliac occlusive disease. In Zorgniotti AW, Rossi G (eds): Vasculogenic impotence. Thomas, Springfield pp 185-215

51. Schweiger H, Zirngibl H, Raithel D (1984) Potenzstörungen vor und nach Beckenarterienrekonstruktion: Objektivierung durch Messung des Penisarteriendrucks. Chirurg 55:95-99

52. Spiro M, Cotton CT (1970) Aorto-iliac thrombendarterectomy. Br J Surg 57:161-168

53. Watt JK, Gillespie G, Pollack JG (1974) Arterial surgery in intermittent claudication. Br Med J 1:23-27

54. Sabri S, Cotton C (1971) Sexual function following aortoiliac reconstruction. Lancet 2:1218-1219

55. Michal V, Kramar R, Bartak V (1974) Femoro-pudendal bypass in the treatment of sexual impotence. J Cardiovas Surg 15:356-359

56. Goldstein 1, Siroky MB. Nath RL, McMillan TN, Menzoian JV, Krane RJ (1982) Vasculogenic impotence: Role of the pelvic steal test. J Urol 128:300-306

57. Michal V, Kramar R, Pospichal J (1978) External iliac "steal syndrome." J Cardiovasc Surg 19:355-357

58. Virag $R$ (1981) Pelvic steal syndrome. Vasa 9:304-307

59. Rotter W, Schürmann R (1950) Die Blutgefäße des menschlichen Penis. Virchows Archiv Bd 318:352-393

60. Wagner G, Green R (1981) Impotence. Plenum Press, New York, London, pp 62-72

61. Bouilly P (1983) Impuissance et facteurs de risque arteriels. These, Paris

62. Wabrek AJ, Burchell RC (1980) Male sexual dysfunction associated with coronary heart disease. Arch Sex Behav $9 \cdot 69-75$

63. Virag R (1984) Impotence: A new field in angiology. Inter Angio $3: 217-220$ 